\title{
Men's Decision-Making About Predictive BRCA1/2 Testing: The Role of Family
}

\author{
N. Hallowell, ${ }^{1,7}$ A. Ardern-Jones, ${ }^{2}$ R. Eeles, ${ }^{3}$ C. Foster, ${ }^{4}$ \\ A. Lucassen, ${ }^{5}$ C. Moynihan, ${ }^{3}$ and M. Watson ${ }^{6}$
}

\begin{abstract}
Men who have a family history of breast and/or ovarian cancer may be offered a predictive genetic test to determine whether or not they carry the family specific $B R C A 1 / 2$ mutation. Male carriers may be at increased risk of breast and prostate cancers. Relatively little is known about at-risk men's decision-making about BRCA1/2 testing. This qualitative study explores the influences on male patients' genetic test decisions. Twenty-nine in-depth interviews were undertaken with both carrier and noncarrier men and immediate family members (17 male patients, 8 female partners, and 4 adult children). These explored family members' experiences of cancer and genetic testing, decision-making about testing, family support, communication of test results within the family, risk perception and risk management. Implicit influences on men's testing decisions such as familial obligations are examined. The extent to which other family members-partners and adult children-were involved in testing decisions is also described. It is demonstrated that mothers of potential mutation carriers not only perceive themselves as having a right to be involved in making this decision, but also were perceived by their male partners as having a legitimate role to play in decision-making. There was evidence that (adult) children were excluded from the decision-making, and some expressed resentment about this. The implications of these findings for the practice of genetic counseling are discussed.
\end{abstract}

KEY WORDS: $B R C A 1 / 2$ testing; men; family; decision-making.

\section{INTRODUCTION}

\section{Predictive Testing for Hereditary Breast Ovarian Cancer (HBOC): Probability and Prevalence}

Between $5 \%$ and $10 \%$ of cases of breast and epithelial ovarian cancer have a strong heritable component; approximately $50 \%$ of these are caused by mu-

\footnotetext{
${ }^{1}$ Public Health Sciences, The Medical School, University of Edinburgh, United Kingdom.

${ }^{2}$ Cancer Genetics Clinic, The Royal Marsden NHS Foundation Trust, London, United Kingdom.

${ }^{3}$ Translational Cancer Genetics Team and Cancer Genetics Unit, Institute of Cancer Research and The Royal Marsden NHS Foundation Trust, London, United Kingdom.
}

tations in $B R C A 1 / 2$ genes. The autosomal dominant mode of genetic transmission of $B R C A 1 / 2$ mutations means that both male and female offspring of a mutation carrier have a $50 \%$ risk of inheriting a cancer susceptibility mutation. While men and women have an equal chance of inheriting a mutation, the risks

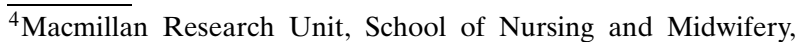
University of Southampton, United Kingdom.

${ }^{5}$ Wessex Clinical Genetics Service, Princess Anne Hospital, Southampton, United Kingdom.

${ }^{6}$ Department of Psychological Medicine, Royal Marsden Hospital, London, United Kingdom.

${ }^{7}$ Correspondence should be directed to Dr. N. Hallowell, Public Health Sciences, The Medical School, University of Edinburgh, Teviot Place, Edinburgh EH8 9AG, United Kingdom; e-mail: Nina.Hallowell@ed.ac.uk.
} 
of developing cancer are much greater in women. Female carriers' lifetime risks of developing breast cancer may be as high as $84 \%$ (Ford et al., 1995), while their risks of ovarian cancer are estimated as between 27 (Whittemore et al., 1998) and 60\% (Easton et al., 1995). Male BRCA2 carriers have a breast cancer risk of $6 \%$ (Easton et al.,1997) and a lifetime risk of prostate cancer of between 6 and 14\% (BCLC, 1999). In the United Kingdom predictive $B R C A 1 / 2$ genetic testing is available to high-risk men and women following the identification of a family-specific mutation in affected relative.

Research indicates that the uptake of predictive $B R C A 1 / 2$ testing in women varies from center to center (for example, 27\% Goelen et al., 1999, versus 58\% Julian-Reynier et al., 2000). Rates of predictive testing in men are similarly variable, but are generally reported as being lower than in women (Bodd et al., 2003; Goelen et al., 1999; Julian-Reynier et al., 2000). Indeed, only $24 \%$ of participants in a recent nationwide study of predictive $B R C A 1 / 2$ testing in the UK were men (Foster et al., 2002). This gender difference may reflect the lack of preventative measures available to men and the fact that the risks of developing cancer are much lower in male carriers compared with females. Alternatively, these differential rates of uptake may be due to the media portrayal of HBOC whose focus on "Breast and ovarian cancer genes" reinforces a common misconception that HBOC is primarily a "gendered" disease (Claes et al., 2003).

\section{Factors Influencing Genetic Testing Decisions}

A range of social, economic, and personal factors has been reported as influencing individuals' decision-making about genetic testing. In the case of $B R C A 1 / 2$ testing - these include the desire to generate information for other family members (Hallowell et al., 2003), the need to gain information to facilitate decisions about prophylactic surgery or surveillance (Foster et al., 2002), fears about life insurance, or job discrimination (Armstrong et al., 2000; Van Riper and McKinnon, 2004), anxiety about cancer risks (Brandt et al., 2002), ethnicity, and/or the identification of a mutation within the family (Armstrong et al., 2000).

This paper focuses on an alternative source of influence on testing decisions which has received much less attention in the literature-other family members. The study of familial influences on decisionmaking can be seen as important for the following reason. Genetic tests necessarily implicate biological kin; consequently, other relatives may have an interest in individuals undergoing testing, particularly if the test result reveals information about their risk status. Thus, individuals may choose to undergo testing even when it is not in their best interests in an effort to please their relatives. Furthermore, one of the ethical principles underpinning genetic counseling services is that the decision to undergo testing should be freely taken by individuals (Nuffield Council of Bioethics, 1993). Thus as Haites (2003) notes, genetic counselors have a duty to ensure that individuals are not being pressurized into testing against their will. While, the idea that genetic testing decisions remain free of any form of external influence may be impossible to obtain in practice, it has been argued that, at the very least, genetic counselors should not only be aware of, but also take steps to reduce familial influences on testing decisions (Liede et al., 2000).

\section{Familial Influences on Genetic Testing: The Empirical Evidence}

Previous research suggests that familial influences on genetic testing decisions may be both implicit and explicit. Studies of women undergoing $B R C A 1 / 2$ mutation testing suggest that many women undergo genetic testing primarily to obtain information so that their relatives can access predictive testing or other health services (D'Agincourt-Canning, 2001; Hallowell et al., 2003). Both D'Agincourt-Canning, (2001) and Hallowell et al. (2003) have argued that genetic testing empowers these women, because it enables them to act, or present themselves as moral agents. However, while these individuals may intentionally forfeit their right to remain ignorant of their mutation status, this does not mean their decisions are free of external influence, because arguably, they are responding to external, if implicit, pressures to conform to social expectations about mothering and its related duties and obligations (Hallowell, 1999).

While familial obligations may implicitly shape testing decisions, previous research suggests that in some cases familial influences may be more explicit. Research on men's decision-making about genetic testing, while limited, suggests that some men may undergo genetic testing against their will as a result of explicit pressure exerted by family members. A recent study of cystic fibrosis carrier screening observed that female relatives (wives, sisters, and mothers) assumed the responsibility for organizing genetic testing within the family, they encouraged their reluctant 
male relatives to undergo carrier testing and, in some cases, phoned the clinic and arranged appointments for them to attend (Fanos and Johnson, 1995). Likewise, Liede et al. (2000) recently reported that a small proportion of the men in their study of predictive $B R C A 1 / 2$ testing described their reason for having predictive testing as "family recommendation." The authors comment that this finding raises doubts about the extent to which some testing decisions can be seen as freely taken, and note that practitioners should take these familial influences into account when counseling. Finally, Culler et al. (2002) report that over $80 \%$ of their sample of men recruited in a prostate cancer clinic indicated that they would undergo a hypothetical genetic test for prostate cancer if their spouse recommended it.

Thus, previous research suggests that "family"both the actions of one's relatives and one's internalized obligations toward these relatives-may exert considerable pressure on genetic testing decisions. These observations raise interesting research questions that were explored in the current study. First, do men, like their female counterparts, perceive familial obligations as influencing their genetic-testing decisions? Second, to what extent are other family members involved in decision-making? Do female spouses/partners or children merely "recommend" that their partners/fathers undergo testing, or are they more actively involved in making the decision?

Using data collected in interviews with men who had undergone $B R C A 1 / 2$ carrier testing, their partners, and their adult children, this paper describes men's motivations for undergoing $B R C A 1 / 2$ predictive testing and demonstrates that family members see themselves and others as having a legitimate role to play in decision-making. It is argued that the data suggest that decision-making about genetic testing should be seen as a family affair rather than an individual choice.

\section{METHODS}

\section{Recruitment}

Following receipt of ethical approval for the study, male $B R C A 1 / 2$ carriers and noncarriers from two regional genetics centers in the UK were approached for participation. A letter from the clinician responsible for their care was sent to eligible men who had received a genetic test result. Other family mem- bers were recruited using snowballing methods. The male patient was given written information to pass on to his partner (who might/might not be the biological mother of their children) and eldest adult ( $>18$ years) child. This information briefly outlined the study and invited family members who were interested in participation to contact the research team for further information.

Initially, we intended to recruit only fathers of adult children; however, as the study progressed we felt it was important to include some families with younger children or men who had no children at all, with the view to exploring their motivations for testing. In these cases, the children were not approached with a view to participation.

A total of 29 participants consented to participate. This included 17/28 men (5 carriers; 12 noncarriers), $8 / 15$ partners ( 3 partners of carriers; 5 of noncarriers), and $4 / 8$ adult children (daughters of noncarriers) who were approached. The study included 9 families in which more than one individual was interviewed: 5 couples, 3 family groups (father, his partner, and child) and 1 father-daughter pair.

\section{The Participants}

All the participants were either of White European or Ashkenazi Jewish descent. The men were aged between 39 and 75 years (median 55 years), their partners 45-60 years (median 51 years), and children $19-37$ years (median 25 years). Over $50 \%$ of the men were in professional occupations; the remainder was a mix of semiprofessional and semiskilled manual workers.

Sixteen men (5 carriers, 11 noncarriers) had children and of these, 13 had one or more daughters and 10 one or more sons. Fifteen men were currently living with a long-term partner. In only one case was the long-term partner not the biological mother of any of the children in the family. Twelve men had adult (18+ years) children at the time of the inter view.

The men reported between 3 and 7 first- and second-degree relatives affected with either breast, ovarian, prostate, or colorectal cancer. None of the interviewees had been diagnosed with cancer. The interviews occurred between 8 and 74 months (mean 26 months) following the receipt of DNA test results. Eight men had received their results within 2 years before the interview and 9 over 2 years ago. 


\section{Data Collection and Analysis}

Data were collected using in-depth interviews. These were carried out either face-face $(n=13)$ or by telephone $(n=16)$ (depending on the participants' preferences). At the start of the interview participants were asked to "... go back to the beginning and tell me about how you first became aware of the family history of cancer and that you (your father/partner) could have genetic testing. What happened then and what has happened to you and your family since." In most cases this generated a long narrative about the family history of cancer, the participants' views on and involvement in genetic testing/decision-making and how they learnt of the test results and their feelings about risk. A set of prompts based upon the following themes: experiences of cancer and genetic testing, decision-making about testing, family support, communication of test results, and risk perception and risk management was used to follow up issues raised by the participants.

With one exception (a partner who requested that the interview was not taped) all the interviews were audio tape-recorded with consent. In two interviews, the recorder failed, and notes were taken; in a further case the tape failed before the interview was completed. Verbatim transcriptions were obtained of the taped interviews. A thematic analysis of the transcripts and interview notes was undertaken using the method of constant comparison (Strauss and Corbin, 1990). Following intensive reading and rereading of the transcripts and notes a coding frame was developed to enable the identification of recurrent themes in the participants' accounts. The data was initially read for accounts of decision-making and accounts indexed using primary codes, for example, influences on decisions, involvement in decisions. Secondary codes emerged from this initial reading (for example, responsibility, rights, duties, resentment, exclusion, and inclusion) and the transcripts were reanalyzed using this coding frame. Both within- and betweengroup comparisons were drawn to determine whether differences existed between carriers' and noncarriers' (and their partners') accounts. No differences were noted between the responses of members of noncarrier and carrier families within this sample. Any differences that existed between different types of family members are described below.

The following sections focus upon why these men came forward for testing and the extent to which other members of their immediate family were involved in decision-making. The frequencies with which some responses occurred are noted in the presentation of the results to provide an indication of their representativeness within this data set.

\section{RESULTS}

\section{Prior Awareness of Family History}

Before discussing the men's motivations for undergoing predictive testing it is important to look at the context in which these decisions are taken, particularly the men's knowledge of their family history of cancer. In all cases, the men reported that the cancer in the family was common knowledge. In some families it was referred to as a "voodoo" or "a curse" on the family. As Alan, whose mother and aunts and sister had all died at the age of 51, said,

\footnotetext{
And of course by this time we were thinking, it must be voodoo! Someone's put a curse on this family. And it was quite terrifying, because my uncles all died of heart attacks, and my aunts were all dying of cancer. So there was something really odd with this family ... we were brought up with this terror of cancer. I've been living with it since I must have been four, knowing people are dying of this terrible Big C. (Noncarrier, 2 children)
}

Others described longstanding myths about the cancers in their family, these included: ideas about the ages at which cancer would occur, or which relatives were most at risk; for example, Airan reported that in his family it was commonly held that cancer would "skip generations." While many men reported a long-term awareness of their cancer family history, and realized that they and other family members were at-risk, all were unaware of the possibility of genetic testing until other family members, usually sisters, became involved with cancer genetic services. Two men were aware of the scientific explanations of HBOC prior to their involvement in predictive testing, the rest were not. However, contrary to our expectations, only three men in the present study reported being surprised or shocked upon learning that the autosomal dominant mode of genetic transmission of BRCA1/2 mutations meant that they could have potentially passed on a mutation to their offspring. As Robert explained,

I can see parts of me in my grandchildren and I can see a part of me in my children. And I do know in the broad spectrum that we do pass on our genes to our children for good or for evil, for whatever they are. And so it didn't cause me any concern of any worry or 
any problems whatsoever that men were capable of passing on genes which would only affect women, or women would pass them on which would affect only men. (Noncarrier, 3 children)

[Jacob] I think that if the child's made up of the mother and father's genes it's obvious it's going to go across. I mean we carry all sorts of things that our parents had don't we. (Noncarrier, 1 child)

With three exceptions all the men said they had immediately decided to seek predictive testing, once they became aware of its availability.

\section{Motivations for Undergoing Predictive Testing}

Although a few men were curious about their own risks, in all cases testing was reported as motivated by a desire to obtain information for their kin. All of the men in this study said they had undergone testing because they felt they had an obligation to their children determine their carrier status. As Mike (Noncarrier, 2 children) commented: "The risk to me wasn't that big, that would affect my health and me that much. I just wanted to know for the benefit of others." Likewise, Kevin said that he went for testing despite worries about what the test might reveal about his own health expectations because he had a status:

[Kevin] I was concerned about the future of my sons, because obviously if I carried the gene there was a chance that they would. So obviously I needed, it was a responsibility to them as well. (Noncarrier, 2 children)

All spoke of a moral imperative to care for their children and acknowledged that this could be achieved by generating information about their carrier status. These men saw the information revealed by genetic testing as information their children ought to have insofar as it would confirm their risk status. The perceived benefits of testing were twofold. As Jeremy said,

If I was able to identify that I had it, then there was a possibility that the girls had it... And if I did have it then, you know I could warn them to be careful. But if I didn't then, you know one less thing for them to worry about. (Carrier, 2 children)

Thus, learning that one was a noncarrier could alleviate worry about one's children and more importantly, remove the children's anxiety about developing cancer. However, even if testing identified a mutation and confirmed that their children were at increased risk, these men reasoned that their daughters and granddaughters could use this knowledge to obtain testing for themselves or surveillance and support. As Tom (Carrier, 4 children) said: "I thought they ought to know, so that they themselves could have tests to see if they were carriers." Similarly, Karl explained that he had undergone testing so that in the event his result proved mutation positive his daughter could obtain better surveillance or an early diagnosis:

\begin{abstract}
If I had never had the gene test then I wouldn't know if I had it or not. Then as she got older she could have the gene. You don't know. But if she'd got the gene, then if she got anything wrong with her, they might look at her sooner and that, keep an eye on her. That's the main reason I suppose I had it done. (Carrier, 2 children)
\end{abstract}

Finally, two men talked about how genetic test results could be used to facilitate reproductive decisions. Both were of the opinion that at-risk individuals had a duty to determine their carrier status prior to childbearing and that confirmed carriers had a duty not to reproduce, as Karl said:

If you've got it in the family, then I think you ought to have a test really.

NH Why do you think you should have it?

Well obviously if you know you've got it you've got it, then if you're younger and you've got no children at the time, then you can make up your mind if you want to have children or not really. [Childlessness] It's the only way to stop it really ain't it? Somebody's got to take that line somewhere. Somebody's got to say to somebody "well we're not going to have no children" if you've got the gene, if you've had the test and you've got the gene.... So if everyone said no I ain't going to have any more children, see, you would stop it, you would stop it dead then, stop the gene going any further. (Carrier, 2 children)

Percy, the only childless man in the study, described how he and his sister had decided not to have children (before predictive testing was available) so they could "stop this [cancers]" in their family. In Percy's view, his relatives had a similar duty to put an end to the "suffering" his family had endured. He talked at length about his own and his sister's anger at other family members who had refused to confirm their carrier status:

We're angry with the people who either haven't been for the test or found out the results of the tests. Because it's as if OK their kids that they've got now, they could go through a lot of suffering needlessly 
or the kids they might have then go on to a lot of needless suffering. And we've both seen enough of that. (Noncarrier, 0 children)

Although the majority perceived the knowledge generated by genetic testing as beneficial, insofar as it could potentially alleviate worry or facilitate access to health services, this was not true of all. Two men described how in coming to a decision they had reflected upon the psychological burden of knowing that one was at a high risk of developing a potentially fatal disease. In contrast to the majority of men in this study, these men reported that the decision to undergo testing constituted an ethical dilemma-it involved them in weighing up the benefits and harms of genetic knowledge. Thus, both described themselves as undergoing a long period of deliberation prior to testing:

[John] I was a little hesitant about whether it was a good idea or a bad idea, because it seemed to me you could sort of argue that if it turned out bad [mutation positive] that would simply increase the level of worry for my children. (Carrier, 3 children)

Likewise, Airan (Noncarrier, 2 children) referred to genetic knowledge as "Two-edged" and reported that he had asked himself "Did I want to know?."

\section{Decision-Making About Testing: A Shared Responsibility}

Although most of these men reported that the decision to have testing had required little deliberation, few took total responsibility for that decision. Indeed, many talked about their partners, siblings, and/or cousins' involvement in the testing decision. For example, Michel (Noncarrier, 3 children), who had been advised by his male cousin of the availability of predictive testing, said he and his wife had made a joint decision to proceed "... we both decided I should do it, definitely. She [wife] was very keen." With two exceptions, all the men said that others, most frequently their partners, had played a significant role in the testing decision. Thus, Alan reported that while he and his wife had not had a long discussion about whether he should have the test, they were in total agreement that he should proceed, and accepted joint responsibility for the outcome:

There were slightly anxious discussions of, oh my God, say we discover that it's the wrong-I've got the rogue gene. But then we thought, well at least well, we'll know and then we'll have to deal with that. We'll cross that bridge when we come to it. (Noncarrier, 2 children).
Likewise, most of the partners interviewed confirmed that the decision to undergo testing had been a joint decision. With two exceptions, all the partners described how they had been involved in the testing decision from the outset:

NH: How involved were you in his decision?

[Anna] I'd say I was very involved. But I think we were lucky in that we were in agreement anyway. I don't know what would have happened if say I'd wanted him to have the test and he hadn't. I'm not quite sure what way it would have gone. But as it happened we were both in agreement that this was something that if, when we got the results, it was [mutation] positive that we would be able to do positive things to help our daughters.

Indeed, all the partners indicated that they felt they had a right to help make the decision because it was their children (or their partner) who were directly implicated by the test outcome. As Sarah, John's wife, said: "...things that concern the girls directly as one of their parents ... I thought it was legitimate for me to have an opinion. And I didn't want to be left out of things."

The right of partners to have a say in the testing decision was acknowledged by most of the men in this study. Indeed, in some cases partners appeared to have the final say. As John said,

\footnotetext{
I was a little hesitant about whether it was a good idea or a bad idea, because it seemed to me you could argue that if it turned out bad, that would simply increase the sort of level of worry for my children. I discussed this a lot with my wife, who felt she'd really like to get the test done. (Carrier, 3 children)
}

\section{Decision-Making About Testing: Agreement and Disagreement}

At the time of the interview, all the men and their partners were firmly in agreement that testing was the way to proceed, and partners were not only seen as wholeheartedly supporting, but also as legitimating the view that testing was the right thing to do. Two families reported that there had been some initial disagreement about testing as is illustrated by Sarah and John's case. His initial concern about causing their children anxiety was not regarded as a good enough reason to not proceed by Sarah, who reported actively coercing her husband to take the test using their children's risk and access to screening as leverage: 
[Sarah] My husband was very uncertain as to whether he would even ask for this testing, and I, over quite a long period of time, was urging it .... I was saying it's a good thing to know and you can make more sensible choices the other side of knowing. And he was saying but how good could those sensible choices be and would it really make any difference in the way you-in the way we conducted our lives or differences in the kind of screening the girls did, and would there really be any consequences and what if?

Maureen, was the only partner to express any reservations about her husband Airan's decision to undergo testing. She reported that her reticence had derived from her anxiety about Airan's health and emotional well-being. She said that initially she was of the opinion that it was better to maintain uncertainty about the future rather than have risk confirmed: "[I]t's one thing to know it happened to your relatives, but it's another to actually live with the gene, and I was worried about how much it would unsettle him.” Thus, for Maureen, genetic knowledge was seen as potentially harmful, because it could upset the balance of family life and cause anxiety. Indeed, when asked what she thought about her children's' risk she replied that it was "Too unbearable to think about, I know I just don't want to think about it." However, Maureen, like her husband, had eventually come to the conclusion that he should proceed with testing, partly because she was reassured by the promise of regular surveillance if Airan was identified as a carrier, but primarily because she recognized that he was keen to establish their children's risks:

\begin{abstract}
What swayed me the other way was that it would give him more direct access to having some tests, regular tests, preventative tests, if there was a 50:50. That in the end swayed me and particularly because Airan at that time was quite clear that he wanted to know for the sake of the girls.
\end{abstract}

\section{Decision-Making About Testing: The Role of Children}

While partners appeared to play a major role in decision-making about testing, (adult) children did not. None of the parents reported consulting their adult children about whether or not their father should have a test. Thus, although three of the daughters interviewed were aware their father was going for testing, none said that they had been involved in making this decision. While all the parents interviewed regarded themselves as having a duty to disclose information about the father's involvement in genetic testing to their children, all said they had deliberately managed the timing and content of communication about testing within the family.

Thus, with the exception of a small group of parents who felt that their children had a right to know information that might affect them from the outset, many had not informed their children that their father was having the test or discussed the implications of a positive test result until after he had received his test result. In justifying their decision to keep testing a secret, or limit the disclosure of certain details until they had definitive information to impart, these parents talked about the need to protect their children from anxiety-provoking information:

NH: So you didn't tell her until you'd actually gone through the whole process?

[Barry] No, I thought, well if I get a negative result there's no point in worrying her. (Carrier, 2 children)

Given the small sample size it is difficult to draw conclusions about how parents' failure to involve adult children in genetic testing decisions affected family relationships; however, it is important to note that two of the four daughters interviewed expressed a great deal of resentment that they had not been consulted. This is primarily because they felt, in contrast to their parents, that their father's decision to have testing actually curtailed their healthcare choices. As Ruth, who had been aware her father was going for testing, said,

If I really think about it, there was a little bit of anger towards him for doing it ... for going through it, and feeling the need to go through it, and then potentially putting us in the situation where we would have to think... I'm sure they wouldn't turn round and say, right, OK, you girls, you've got to go for it now, and my brother. But it would be hanging over us. (Noncarrier father)

Rachel was upset she had not been informed that her father had had testing until after the fact, and like Ruth, she felt that her father's decision robbed her of the capacity to make a decision about testing for herself. She said about her father's negative result:

[Rachel] "On one level I was really happy and on another level I was really angry that he hadn't told me he was going for testing. In a sense I preferred 
him not to go to find out anything... I had to stop myself saying "Why didn't you tell me (shouting) all these things, you were going for tests." ... I thought I was in control of what I wanted to know or not want to know about myself, in that I was going to leave it for a while and not think about it." (Noncarrier father)

While both women acknowledged that their parents would not have explicitly encouraged them to seek genetic testing had their father been identified as a carrier, they felt there would have been implicit pressure from their parents for them to undergo predictive testing. Thus, they reasoned that by actually having the test their father had effectively curtailed their choices by undermining their right to not know information about themselves.

\section{DISCUSSION}

In summary, all the men in this study described their decision to have genetic testing as influenced by their obligations to other family members, primarily their children. All reported having undergone testing with the intention of providing their children (and grandchildren) with information that could alleviate their anxiety and/or enable them to make informed decisions about their future healthcare. However, while for most the decision to have testing was described as straightforward, this was not the case for all. Genetic test results may indeed, allay anxiety about risk, but they may also result in increased anxiety, depending on the outcome. Thus for a minority, genetic testing presented them with a conflict of duties-their duty to warn their children of their risks versus their duty not to harm them by causing emotional distress.

All the men and their partners acknowledged that their children had a right to know their carrier status and that they, in turn, had a duty to ensure their children received this information; either by undergoing testing or by helping their partners to reach a decision. Adult children, on the other hand, were not seen as having a role to play in decision-making, or at least their parents did not perceive themselves as having an obligation to consult them about this matter. However, although parents' decisions to exclude their children from decision-making may have been motivated by the best of intentions, their actions were interpreted by some of the children as paternalistic. These children talked of their right to remain in ignorance of their risk status and, therefore, re- garded themselves as having a legitimate role to play in testing decisions.

It can be argued that the data presented above demonstrate that "family" impacts on predictive testing decisions in different ways. There was evidence that the men who took part in this study not only acknowledged, but also accepted and embraced the existence of familial influences on their decision to undergo $B R C A 1 / 2$ testing. In the concluding part of this paper we will explore the implications of these findings for genetic counseling practice.

Previous studies suggest that men who have a family history of HBOC worry about their daughters' risk status (McAllister et al., 1998) and undergo $B R C A 1 / 2$ testing to establish their risk status for the sake of their children (Daly et al., 2003; Goelen et al., 1999; Liede et al., 2000; Lodder et al., 2001). Similar results were generated in the present study. There was evidence that the men worried about their children's risks and had undergone testing specifically to provide information about/for their children. However, while genetic testing may have been driven by beneficent motivations it was also constructed as a parental responsibility. All the men reported that they had an obligation to determine their carrier status, in order that they might increase their descendants' healthcare choices or allay their anxiety about their cancer risks. Similar justifications for genetic testing decisions were observed in our earlier study of women undergoing BRCA1/2 mutation searching (Hallowell et al., 2003), in which we argued, following O'Neill, (2002) that the existence of such obligations undermines the view that genetic testing decisions can, or indeed, should, be based upon the purely individualistic or egocentric conception of autonomy that underlies many models of medical decision-making (see Beauchamp and Childress, 1994):

\footnotetext{
The familial nature of genetic information compromises the possibility of making an autonomous decision about genetic testing on two counts. First, an individual's DNA-test results have direct implications for biologically related kin and second, the persons who undergo testing have social obligations towards these kin. For these reasons we would argue that the decision to undergo testing cannot be entirely egocentric, but may be influenced not only by one's awareness of others' interests in obtaining genetic information, but also by one's own interests in maintaining relationships with these interested parties. (Hallowell et al., 2003)
}

In addition to implicit influences such as the need to act, or present oneself as acting, as a 
responsible parent or a moral agent (D'AgincourtCanning, 2001), there was evidence that the men in the present study were explicitly influenced by other family members - the mothers of potential mutation carriers. With two exceptions, the decision to undergo genetic testing was reported as actively involving both parents. Most men described their partner's input, agreement, endorsement, and support as not only welcome, but in most cases, explicitly sought. Interestingly, this finding contrasts with those obtained in our recent study of women undergoing mutation searching (Hallowell et al., 2002). While the women in this earlier study reported that their partners had supported their decision to undergo testing, most described themselves as assuming total responsibility for that decision. Thus, very few women reported actively seeking their partner's advice; in most cases the decision to undergo mutation testing had been presented to male partners as a fait accompli rather than as an issue requiring discussion. The difference between the findings of the present study and this earlier work may derive from the fact that the risks of cancer are greatly elevated in female $B R C A 1 / 2$ carriers compared with males, and some types of risk management (for example, prophylactic mastectomy/oophorectomy) that are available to women while more efficacious, are physically and emotionally more invasive. Thus, $B R C A 1 / 2$ test results may be perceived as having a greater personal relevance for at-risk women than they do for at-risk men. Consequently, if mothers are potential carriers rather than fathers, the responsibility for decision-making may be assumed by women or relinquished by their partners because at-risk women are potentially faced with higher risks of disease and making more difficult risk management decisions (Hallowell, 1998).

While the data indicates that partners' views were very influential in the present study, there was no evidence to suggest that these men perceived themselves as pressurized or coerced by their partners into having a genetic test against their will. Indeed, as far as most of the men were concerned, because they and their partner shared the responsibility for caring for their children, their partner had a right to be included in decision-making about testing. Likewise, partners interpreted their duty to care for their children, as meaning that their views should be taken into account. In summary, the data suggests that the decision to undergo $B R C A 1 / 2$ predictive testing may be less an exercise of individual choice than a family affair.

At this point one can ask whether genetic testing decisions should be seen as completely personal and free choices? Clearly, we would not advocate that at-risk individuals underwent genetic testing against their will, but given that decisions are taken within a familial context and given the familial nature of genetic information, is it realistic to require that a decision to undergo genetic testing is free of familial influence, as Liede et al. (2000) would seem to suggest:

It is important for practitioners in familial cancer to be aware of potential pressures - either for or against testing - that may exist within families and help promote autonomous decisions. (Liede et al., 2000)

Statements such as this serve to reinforce the widespread belief that testing decisions should, or can, be expressions of individual choice, given the right type of counseling and support (see also Haites, 2003). However, the data collected in this study suggest that the eradication of familial influences on genetic testing decisions may be more difficult to achieve than Liede et al. (2000) propose. First, because decisions about genetic testing take place within a social context of preexisting familial obligations, genetic testing or the management of genetic risks has come to be constructed as a relational responsibility-an expression of moral agency (Hallowell, 1999; Hallowell et al., 2003) - or a social duty (Petersen and Bunton, 2002) rather than an individual right. Thus, while DNAtesting may indeed, further individual choices, insofar as it reveals information about an individual's genetic risks, it also provides information that others can use to inform their healthcare choices. From the point of view of different family members the former motivation for testing may be deemed as much less important than the latter. Furthermore, as the participants in this study acknowledged, because one's descendants are necessarily implicated by genetic test results, other family members feel they have a right to play a part in genetic testing decisions.

Arguably, these observations suggest that we need to adopt an alternative view of decision-making about genetic testing; one that acknowledges that genetic testing, like all other forms of human activity, is situated within a social context. Human beings as social beings, exist within a network of relationships that is structured by duties and obligations. Thus, we suggest that perhaps a more realistic goal for genetic counselors should not be the elimination of familial influences per se as Liede et al. (2000) advocate, but to help counselees acknowledge the extent to which their actions are born out of a sense of responsibility or explicitly influenced by their relatives or indeed, other factors. 
While, all the parents in this study appeared to agree that testing was the right way to proceed, there was evidence that the daughters interviewed were more ambivalent about their father's involvement in testing. Even though the study only included a very small number of adult children (and no sons), their responses suggested that parents' motivation to obtain genetic information for their children may not always be appreciated or even desired by their offspring. Clearly there is a need for genetic counselors to advise parents that their children may not want to know their risk status and thus, may wish to be involved in decisions that will ultimately affect themselves. Moreover, the reactions of two daughters in this study suggest that parental subterfuge about genetic testing has the potential to inflict damage on family relationships, for example, by generating a lack of trust in general (Juengst, 1999; Wexler, 1995). Arguably counselors need to encourage fathers (and mothers) to be truthful with and consult their children from the outset and support them in this endeavor.

\section{Limitations of the Present Study and Future Directions}

Finally, it is appropriate to discuss some of the methodological limitations of this research. First, the size of the sample. For ethical reasons we asked the fathers to recruit their partners and adult children to the study. The adoption of family snowballing methods was favored for two reasons. First, it meant that family members' privacy was respected, for they had to opt into the study. Second, at least in theory, it meant that we would only recruit participants who knew that their partner/father had undergone testing and were aware of the presence of a mutation in their family (See McAllister, 2004). However, in practice recruiting adult children to the study proved to be problematic. While carrier men were prepared to contact their partners, with one exception, a man whose daughters had already undergone predictive testing, none of the male carriers were prepared to approach children with an at-risk status to participate in the study. Indeed, of the 12 men interviewed with children aged over 18 years, 5 did not want to approach their children, citing anxiety about causing their children worry about their carrier status as the reason. It must be noted that two of these fathers were noncarriers, who expressed the worry that talking about genetic testing, even though it was no longer an issue for their immediate family, may have made their children anxious. While we respected these parents' wishes, it limits the conclusions that can be drawn from this study, for it is possible that those children who did take part may have a particularly idiosyncratic view of their father's involvement in genetic testing. Clearly, there is a need for more research that looks at the views and information needs of the adult children (both daughters and sons) of mutation carriers and noncarriers.

Second, it must be noted that, with one or two exceptions, there was a striking lack of disagreement about genetic testing reported by the men and women in this study, which may reflect the fact that it only included families in which testing had taken place. However, we also need to acknowledge that the participants may have been motivated by a desire to present themselves in a positive light. Bearing this in mind, it is perhaps not surprising to observe that the parents in this study failed to portray themselves as having fundamental objections and disagreements about testing, given that genetic testing, in general, is such a morally charged issue. These observations suggest that there is a need for prospective studies that focus upon family members' involvement in genetic testing decisions and, perhaps more importantly, more research on families where genetic testing has been refused.

\section{CONCLUSIONS}

In conclusion, this study of decision-making about genetic testing in families in which the father had undergone $B R C A 1 / 2$ predictive testing suggests we need to adopt a different, or less individualistic, conception of decision-making about genetic testing. The data presented above indicate that "family" plays an important role in testing decisions, a role that cannot be overlooked and may not be eradicated by genetic counseling (Juengst, 1999). Maybe it is time that we accepted that when it comes to genetic testing the "patient"/"counselee" really is the family. Those who provide genetic services should not only be aware of implicit and explicit family influences on decision-making, but also embrace them.

\section{ACKNOWLEDGMENTS}

We would like to thank all the research participants, who were so generous with their time, Fiona Lennard, Sue Davolls who provided ongoing 
support from the inception of the project until its completion. We are extremely grateful to Julia Lawton who, as always, provided some very insightful suggestions about the ways in which this paper could be improved. This research was supported by Cancer Research UK (Grant No: C1226/A140) awarded to M. Watson, C. Foster, C. Moynihan, and N. Hallowell.

\section{REFERENCES}

Armstrong, K., Calzone, K., Stopfer, J., Fitzgerald, G., Coyne, J., \& Weber, B. (2000). Factors associated with clinical $B R C A 1 / 2$ testing. Cancer Epidemiol Biomarkers Prev, 9, 1251-1254.

Beauchamp, T. L., \& Childress, J. F. (1994). Principles of Biomedical Ethics, 4th ed. New York: Oxford University Press.

Bodd, T. L., Reichelt, J., Heimdal, K., \& Moller, P. (2003). Uptake of BRCA1 testing in adult sisters and daughters of known mutation carriers in Norway. J Genet Couns, 12, 405-417.

Brandt, R., Hartmann, E., Ali, Z., Tucci, R., \& Gilman, P. (2002). Motivations and concerns of women considering genetic testing for breast cancer: A comparison between affected and atrisk probands. Genet Testing, 6, 203-205.

Claes, E., Evers-Kiebooms, G., Boogaerts, A., Decruyenaere, M., Denayer, L., \& Legius, E. (2003). Communication with close and distant relatives in the context of genetic testing for hereditary breast and ovarian cancer in cancer patients. Am J Med Genet, 116A, 11-19.

Culler, D. D., Silberg, J., Vanner-Nicely, L., Ware, J. L., JacksonCook, C., \& Bodurtha, J. (2002). Factors influencing men's interest in gene testing for prostate cancer susceptibility. J Genet Couns, 11, 383-398.

D'Agincourt-Canning, L. (2001). Experiences of genetic risk: Disclosure and the gendering of responsibility. Bioethics, 15, 231.

Daly, P. A., Nolan, C., Green, A., Ormiston, W., Cody, N., McDevitt, T., et al. (2003). Predictive testing for BRCA1 and 2 mutations: A male contribution. Ann Oncol, 14, 549-553.

Easton, D., Steele, L., Fields, P., et al. (1997). Cancer risks in two large breast cancer families linked to BRCA2 on chromosome 13 q12-13. Am J Hum Genet, 61, 120-128.

Easton, D. F., Ford, D., Bishop, D. T., \& The Breast Cancer Linkage Consortium. (1995). Breast and ovarian cancer incidence in BRCA1 mutation carriers. Am J Hum Genet, 56, 265-271.

Fanos, J. H., \& Johnson, J. P. (1995). Barriers to carrier testing for adult cystic fibrosis sibs: The importance of not knowing. $\mathrm{Am}$ J Med Genet, 59, 85-91.

Ford, D., Easton, D. F., \& Peto, J. (1995). Estimates of gene frequency of $B R C A 1$ and its contribution to breast and ovarian cancer incidence Am J Hum Genet, 57, 1457-1462.

Foster, C., Evans, D. G. R., Eeles, R., Eccles, D., Ashley, S., Brooks, L., et al. (2002). Predictive testing for BRCA1/2: Attributes, risk perception and management in a multi-centre clinical cohort. Br J Cancer, 86, 1209-1216.

Goelen, G., Rigo, A., Bonduelle, M., \& De Greve, J. (1999). Moral concerns of different types of patients in clinical BRCA1/2 gene mutation testing. J Clin Oncol, 17, 1595.
Haites, N. (2003). The ethical management of genetic testing. Eur J Cancer, 39, 1339-1340.

Hallowell, N. (1998). "You don't want to lose your ovaries because you think 'I might become a man'.”: Women's perceptions of prophylactic surgery as a cancer risk management option. Psychooncology, 7, 263-275.

Hallowell, N. (1999). Doing the right thing: Genetic risk and responsibility. Sociol Health Illn, 21, 597-621.

Hallowell, N., Foster, C., Eeles, R., Ardern-Jones, A., Murday, V., \& Watson, M. (2002). Genetic testing for women previously diagnosed with breast/ovarian cancer: Examining the impact of BRCA1 and BRCA2 mutation searching. Genet Testing, 6, 79-87.

Hallowell, N., Foster, C., Eeles, R., Ardern-Jones, A., Murday, V., \& Watson, M. (2003). Balancing autonomy and responsibility: The ethics of generating and disclosing genetic information. J Med Ethics, 29, 74-79.

Juengst, E. T. (1999). Genetic testing and the moral dynamics of family life. Public Understand Sci, 8, 193-205.

Julian-Reynier, C., Sobol, H., Sevilla, C., Nogues, C., Bourret, P., \& French Cancer Genetic Network. (2000). Uptake of hereditary breast/ovarian cancer genetic testing in a French national sample of $B R C A 1$ families. The French Cancer Genetic Network. Psychooncology, 9, 504-510.

Liede, A., Metcalfe, K., Hanna, D., Hoodfar, E., Snyder, C., Durham, C., et al. (2000). Evaluation of the needs of male carriers of mutations in $B R C A 1$ or $B R C A 2$ who have undergone genetic counseling. Am J Hum Genet, 67, 1494-1504.

Lodder, L., Frets, P. G., Trijsburg, R. W., Tibben, A., Meijers-Heijboer, E. J., Duivenvoorden, H. J., et al. (2001). Men at risk of being a mutation carrier for hereditary breast/ovarian cancer: An exploration of attitudes and psychological functioning during genetic testing. Eur J Hum Genet, 9, 492-500.

McAllister, M. (2004). On being used by research participants. In N. Hallowell, J. Lawton, \& S. Gregory (Eds.), Reflections on Research: The Realities of Doing Research in the Social Sciences. Maidenhead, UK: Open University Press.

McAllister, M. F., Evans, D. G., Ormiston, W., \& Daly, P. (1998). Men in breast cancer families: A preliminary qualitative study of awareness and experience. J Med Genet, 35, 739-744.

Nuffield Council of Bioethics. (1993). Genetic Screening: Ethical Issues. London: Nuffield Trust.

O'Neill, O. (2002). Autonomy and Trust in Bioethics. Cambridge, UK: Cambridge University Press.

Petersen, A., \& Bunton, R. (2002). The New Genetics and the Public's Health. London: Routledge.

Strauss, A., \& Corbin, J. (1990). Basics of Qualitative Research. London: Sage.

The Breast Cancer Linkage Consortium. (1999). Cancer risks in BRCA2 mutation carriers. J Natl Cancer Inst, 91, 1310-6.

Van Riper, M., \& McKinnon, W. C. (2004). Genetic testing for breast and ovarian cancer susceptibility: A family experience. J Midwifery Womens Health, 49, 210-219.

Wexler, N. (1995). Mapping Fate: A Memoir of Family, Risk and Genetic Research. New York: Random House.

Whittemore, A. S., Gong, G., \& Itnyre, J. (1998). Prevalence and contribution of BRCA1 mutations in breast and ovarian cancer: Results from three U.S. population-based case-control studies of ovarian cancer. Am J Hum Genet, 60, 496-504. 